\title{
INTERNATIONAL ENGLISH AND ITS CONSTRUCTION
}

Pam Peters, Macquarie University

Correspondence to Pam Peters: Pam.Peters@ling.mq.edu.au

\section{INTRODUCTION}

Discussions of International English (IE) or English as an international language (EIL) are sometimes clouded by the fact that the terms themselves are subject to alternative interpretations and multiple constructions. Hansen (1997, p. 66) noted the fuzziness of the term IE, and formulated several definitions of it and its occasional substitute "world English" (pp. 62-5), to demonstrate that it may focus on either the functions of an international English or its form. The formal and functional perspectives may in turn be grounded either in linguistic data or abstracted out of it, so that the actual base of IE in usage and discourse, and its hypothethical or hoped for realisations, are not clearly distinguished. Treatments of IE tend to be aspirational, postulating a universal medium to meet the English-speaking world's communicative needs - regionally neutral in its linguistic elements and culturally neutral when deployed in actual discourse. Meanwhile fundamental issues such as what functions IE is expected to serve, the linguistic resources for such a desideratum, whether they could form a viable IE code, and which speech community might support its use, need much closer consideration.

In what follows we shall separate the functional and formal approaches to IE, to examine their basis and the kinds of evidence used in discussing each. The paper investigates whether IE can be said to exist in a natural form (spoken or written); and if not, whether (a) it could be constructed, or (b) should be allowed to evolve. In what follows we shall use the abbreviation EIL for the function and IE for the actual realisation(s) of international English, where they need to be distinguished.

\section{INTERNATIONAL ENGLISH AS A FUNCTIONAL MEDIUM, SPOKEN OR WRITTEN}

Hansen's first definition of IE (1997, p. 63) projects it as EIL, an international lingua franca, foregrounding its function as a convergent medium of communication against the otherwise centrifugal effects of different regional varieties. Its widespread use throughout the world prompts the notion of English as the answer to crosscultural and 
crosslingual needs (Smith, 1981). Literal understanding of the prefix inter- also supports this in discussions of English as an international language.

The idea of an international form of English which could be the medium for intercommunication between speakers/writers of other languages has considerable appeal for both L1 and L2 users. For monolingual L1s, especially those with the "monolingual mindset" (Clyne and Sharafian 2008, p.14), an international English would be highly convenient since it seems to absolve them of the need to learn another language - or even another variety of English. Speakers of "inner circle" varieties tend to assume that their own regional variety would also serve as IE. Few (pace Newport (1987)) recognise that the notion of IE puts some obligation on L1s to learn to use a "denationalised" form of their own language, and to be more tolerant of "outer circle" varieties of English (McArthur, 1997, p. 211). But that would certainly be among the hopes of L2s for IE: that it should embrace their varieties of English, and that exonormative reference points and "native-speaker" competence should not be its "norms". Rather it would be defined as a convergent medium for mutual understanding among users of English from both inner and outer circles. The English used by those from Kachru's "expanding circle" (1988) is presumably included as well, because of the now fuzzy boundary between them (McConnell, 2003, pp. 301-2).

The phenomenon of spontaneous convergence in English-language conversations between L2s users of different regional varieties, has been noted by various commentators using terms other than IE/EIL. Crystal (1997, pp. 137-9) depicts a scenario for World Standard Spoken English (WSSE), in which a group of businessmen from India, Africa and the US achieve mutual understanding at the conference table, with the differences in their varieties of English somehow neutralised. In such contexts speakers of indigenised varieties of English might of course shift to acrolectal forms, though Crystal does not suggest this. The French advocate of Globish (Jean-Paul Nerriere) reported similar convergence when he met Japanese and Korean businessmen and conversed in English (McCrum, 2006). Likewise Anna Mauranen (2006) in describing English as a Lingua Franca (ELF), found convergence in the English used by L2 academics from different parts of the world working in Finland. Taking these examples as evidence of IE in action, we note that it occurs in both European and Asian contexts where English serves the lingua franca function. But it raises the question as to what the communicative common denominators are. Are they in the motivations of the participants to achieve successful interaction? Or in the modes of discourse and the international business/academic contents of the conversation? It is most gratifying when such communication takes place, though it begs the question as to what exactly has been communicated. Empirical and compar- 
ative testing of what understandings are transacted in a variety of ELF contexts is needed, to confirm the functionality of this construction of spoken IE.

The idea of a written IE which might serve as the standard of English for print and internet purposes (McArthur, 2002, p. 6) is of equal interest for most L1 and L2 users. Notionally it would provide them with a region-free medium, and allow them to communicate with readers throughout English-speaking world without carrying a commitment to either BrE or AmE style, and their political and cultural implications. This is certainly a desideratum for international publishers - to be able to publish a single English-language version of a text for global markets, rather than having to negotiate separately edited versions for different sectors of the world. The desirability of having a regionally neutral version of English is just as important in Internet communication, for writers who wish to transcend the regionally marked styles and their particular geolocation. Yet this hopedfor regionally neutral IE/EIL is still an ideal. In any printed text there are elements of morphology, orthography and punctuation which tend to be indexical of British or American regional style for L1 readers (Peters, 2009, forthcoming). They effectively present dual standards (Leitner, 1992), rather than a single IE code as postulated at the centre of Goerlach's and McArthur's concentric models of world English (labelled as "World Standard English" in the latter; see McArthur, 1997, pp. 97, 101). The nonalignment between the models and conceptions of IE, and the regional varieties of English calls for separate discussion, in the following section.

\section{INTERNATIONAL ENGLISH AS A VARIETY IN A PLURICENTRIC WORLD}

The term "International English", when capitalised, seems to denote a variety of English like most of those noted in the second and third circles of Goerlach's model (Australian English, Aboriginal English, etc.) and in the outermost circle of McArthur's model. Both models contain a mix of emerging regional standards - some rather notional, e.g. Antipodean English (Goerlach), South Asian Standard(ising) English (McArthur), which fit geographically into the two-dimensional geometry of the model, but whose status is different from that of the observable varieties of the region. A three-dimensional model (three-tiered hierarchy, like that sketched by Leitner (1992, pp. 225-7)) would better accommodate the incipient regional standards which must currently be abstracted from the relevant regional varieties, and distinguish them from the varieties which are now universally recognised.

A further problem with the present two-dimensional concentric models is that they present their IE equivalent at the heart of their models, as if it were the common core of 
all the regional varieties. We shall revisit the question of the "common core" when discussing the actual form of IE in section \#4 below. But the primary problem in terms of representing IE within these models is that the conceptualisation we have discussed so far is not of a regional variety but a supraregional medium. Its speech community is not based in any one of the geographical regions shown, or a contiguous group of them. Instead it draws variably on speakers of any of them as they coincide in a particular communicative context. This incidentally means that it is more difficult to point to a natural speech community through whom IE may be developed and transmitted as a supervariety. Because it is a functional variety or register of English, it stands outside the present regional models of English. Put another way, we need a model which can accommodate functional varieties of English as well as the strictly geographical parameters of variation.

An alternative response to the limitations of the present models of world English is to conceptualise IE as the collective sum of all varieties from inner and outer circles (= world English). This was the inspiration behind the ICE project (International Corpus of English), which was established to include corpora from regions where English is the national language, as in Australia, and where it is an official alternative or auxiliary language, as in Singapore and Hong Kong (Greenbaum, 1996). By including the English of both L1 and L2 users, it offers that "more symmetrical understanding of pluricentricity of English" and attaches "multiple norms" to the concept of IE (Clyne and Sharafian, pp.12, 18). The forms of IE are of course likely to diverge in different parts of the Englishspeaking world. Those identified in EuroEnglish by Seidlhofer et al. (2006) and by McLellan (2007) for an Asian Lingua Franca are rather different, reflecting the different L2s which form the substrate for those speakers. So with divergent norms characterising the pan-continental versions of IE, its realisation remains centrifugal rather than centripetal. Any conception of IE as homogenous is problematic - a theoretical construct and contextual phenomenon, but not a convergent set of empirically based norms.

\section{CONSTRUCTING IE: THE ESSENTIAL FORMS}

Those engaged in English language teaching are typically positive about the prospects of engaging their non-English-speaking students with some form of IE. Its functional value is obvious. Modiano (1999) describes it from a European perspective in the name of mid-Atlantic English, a blend of BrE and AmE which embraces both in its grammar and lexicosemantics. Those who teach ESL from the communicative perspective are naturally inclined to EIL in terms of its function, but must also grapple with questions as to the form of IE. The most effective communicative syllabuses have a supporting 
strand of structural elements to expand the students' linguistic competence as well. Pragmatic competence sits alongside linguistic competence (Bachman, 1990), and is embedded in the realisation of more and less direct speech acts (Clyne and Sharafian, p. 10). Linguistic competence is essential if students are to make professional use of English as a second language (i.e written as well as spoken).

An ELT syllabus - whether primarily communicative or not - calls for language targets. The need to devise a limited form of IE for pedagogical purposes surfaced periodically during the last century, in repeated efforts to create a set of essential English elements as the basis for communication and further English language acquisition. The core vocabulary of 850 words ("Basic English") created by Richards (Ogden 1930) was one such, consisting of everyday nouns, adjectives and some "operations" (a miscellany of common verbs, adverbs, prepositions and pronouns with which simple statements could be formulated. The word list reflects the British culture of the times, with items such as "servant" and "coal" included. Somewhat later Quirk (1981) described a "Nuclear English", focusing on an essential English syntax and the most transparent grammatical alternatives, e.g. questions formulated as statements but made interrogative with rising intonation: It is raining? - rather than by subject-verb inversion: Is it raining? He was nevertheless acutely aware of the minimalism in foregrounding such alternatives, and of his time, in arguing that they should always allow for elaboration in the direction of more expansive native-speaker norms. Most recently Frenchman Jean-Paul Nerriere publicised his Globish (McCrum, 2006), a repertoire of 1500 English words and syntactic elements to be used as a lingua franca for international business communication.

Such attempts to construct a cut-down form of English for international purposes provide targets for ELT or ESP, though their contents were developed on the basis of native-speaker intuitions, without empirical input. The need for empirical evidence on the actual differences between L1 and L2 varieties of English was part of the motivation for the ICE project, which coordinated the development of written and spoken corpora of inner and outer circle varieties (see ICE website at www.ucl.ac.uk/english-usage/ice). The potential for intercomparisons between them is now beginning to be realised (as in Hundt and Biewer, 2007). Through this comparative research, the ICE corpora provide empirical identification of "common core" English vocabulary, i.e. those high-frequency items shared by all regional varieties. However research on distilling the common core elements, even from two highly standardised varieties (BrE and AmE), showed that highfrequency items such as prepositions, e.g. apart and aside, still present statistically significant divergences in usage (Peters, 1998, pp. 287-8). The divergent semantics of everyday content words like bring in Australian and Singaporean English serve to show that some 
likely candidates for the "common core" do not get used in exactly the same way in every variety of English. Thus divergences in what might otherwise be IE actually prove more visible from corpus evidence. Large corpora (e.g. the British National Corpus) can provide evidence of the relative frequencies of major and minor alternatives (morphological and orthographic) in BrE, which contrast with the typically singular selections of AmE. Out of these overlaps an international English option can be extracted, for example where BrE uses both -ed and - $t$ with verbs like burn, spelled, -ed is to be preferred for the purposes of IE because it coincides with standard AmE usage (Peters, 2004, pp. 173-4). But the number of cases in which such overlaps in regional variation can yield an international option is not so great. Irreconcilable divergences present themselves both on the surface of language and in the underlying semantics.

Whether constructed on the basis of corpus evidence or linguistic intuition, attempts to identify a common core of English usage for international purposes are always challenged: by representing the language only partially, and by the lack of a language authority to sanction their usage selections throughout the English-speaking world. Though other pluricentric languages have established language academies to endorse standard usage, the English-speaking nations have never succeeded in doing so - either individually, as in many Spanish-speaking countries, or collectively, as for Arabic (Clyne, 1992, p. 463). Attempts to establish an English academy in C18 foundered on the lack of patronage, and because of that perhaps rather English characteristic of being unwilling to submit to regulation and authority. As Johnson put it in the introduction to his Dictionary of the English language (1755):

We live in an age in which it is a kind of publick sport to refuse all respect that cannot be enforced. The edicts of an English academy would probably be read by many only that they might be sure to disobey them.

The absence of an English language academy has meant that the norms of the language have always been established by ongoing consensus and majority practice. Yet the possibility of inducing an ever-increasing speaker-base, spread across almost all continents, to embrace an artificially constructed set of norms in the name of IE, seems more remote than ever. 


\section{CONSENSUS AND EVOLUTION}

The fact that English is increasingly used by larger numbers of L2s than L1s (Crystal, 1997, pp. 60-1) is likely to have profound effects on its evolution and the norms of international English. In countries where English sits alongside one or more other major languages, its place in the education system, at primary, secondary and tertiary level (McConnell 2003, pp. 305-9), is the key to its growth and functionality within the community, as well as the lectal range exercised by its users. They are subject to both local and global pressures, i.e. "glocalisation" (Pakir, 1997) as it has been dubbed in the Singapore context. For Singaporeans, English has on the one hand to represent their local identity and connect with their underlying Asian culture, on the other it is their means of connecting with global business developments, in which an international form of English is essential. While Singaporean English below the acrolectal level becomes the language of identity, their international English used for more formal purposes is likely to borrow from the familiar standard forms of both BrE and AmE. The postcolonial generation of Singaporeans has a lower commitment to British norms, as shown in data from the Singapore ICE corpus, where grammatical preferences such as using the mandative subjunctive, aligns it more with American usage (Peters, 2009a, pp. 129-30). A mix of BrE and AmE features can also be seen in Mainland Chinese English, in sources such as the China Daily newspaper, and in the spellings and definitions of dictionaries (Peters, 2003, pp. 36-7).

This spontaneous blending of elements from BrE and AmE suggests that L2s seeking to communicate in international forms of English are not necessarily committed to one or the other because of past history or the present political balance of power. Of course, AmE is a potent force because of the pervasiveness of American media and other economic activities. But the norms of AmE are not necessarily endorsed simply because of such pressures. Rather it may simply be that the norms of written AmE are typically more regular and uniform than the BrE counterparts, and that they are preferable to L2 users of English for that reason.

Data on orthographic preferences extracted from the Langscape surveys 1998-2001, conducted through the international magazine English Today, suggest that L2 users of English, whether from Europe or Asia, are often more inclined to the regular (i.e. rulegoverned) alternatives when presented with the choice. In the table below, the returns on two spelling and two punctuation questions are presented, to provide comparisons between British and American usage, as well as European and Asian preferences. 


\begin{tabular}{|l|c|c|c|c|}
\hline & Am \% & Br \% & European \% & Asian \% \\
\hline usable & 68 & 48 & 52 & 62 \\
useable & 32 & 52 & 48 & 38 \\
stony & 76 & 52 & 64 & 79 \\
stoney & 24 & 48 & 36 & 21 \\
Dr. & 87 & 25 & 17 & 63 \\
Dr & 13 & 75 & 83 & 37 \\
Dept. & 87 & 47 & 40 & 71 \\
Dept & 13 & 53 & 60 & 29 \\
\hline
\end{tabular}

Table 1

Final results of Langscape survey for e-dropping and use of stops in abbreviations/contractions (1)

These are of course rather small points of variation in written IE, but the results are symptomatic of larger regional differences. The American/British differences show the always greater American commitment to more inclusive orthographic rules, e.g. the principle of dropping $e$ before suffixes beginning with a vowel (Sigley, 1999); and the American editorial practice of giving a stop to all abbreviations, not just those which curtail the stem as in $\mathrm{BrE}$ (Peters, 2004, p. 126 (see contractions)). On the spelling issue, L2 users from both Europe and Asia (especially the latter) were more inclined than the British to go for the regular spelling. On the punctuation issue, however, the European responses remained close to (just under) the British, whereas those from Asia were much more advanced in the direction of the American. These results suggest that L2 users (especially in Asia) are generally better disposed to the regular orthographic variants than the British. They line up also with Algeo's (2006) comment that BrE is generally more favoured in Europe, and AmE in Asia.

The orthographic data shown in Table 1 nevertheless suggests that the forms of IE forged by consensus may not always favour the AmE written standard. They will probably vary with the item, and be differently weighted in the European and Asian contexts. This confirms the general point made earlier (section 3), that the emerging norms of IE are quite likely to vary with the region. It confirms that they may not be aligned exactly with either BrE or AmE, but involve some reconfigurations of elements of both. The endproduct of the evolutionary process is not to be predicted on the basis of L1 usage, but L2 preferences. The multiplicity of speech communities using English around the world will ensure that written IE will not be entirely homogenous, and spoken IE will certainly present multiple norms. 


\section{NOTE ON LANGSCAPE SURVEY DATA}

1. The numbers of respondents to the two surveys were as follows:

- on diacritic e: Overall response 1106, incl. N.America 175; UK 488; Europe (esp. Sweden, Switzerland, Germany) 251; Asia (esp. Hong Kong, Singapore) 71

- on stops in contractions: Overall response 149, incl N. America 16; UK 37; Europe 11; Asia 38

\section{REFERENCES}

Algeo, J. (2006). British or American English? Cambridge: Cambridge University Press.

Bachman, J. (1990). Fundamental considerations in language testing. Oxford: Oxford University Press.

Clyne, M. (Ed.) (1992). Pluricentric languages Berlin: Mouton de Gruyter.

Clyne, M.; Sharafian, F. (2008). English as an International language: Challenges and possibilities. (this volume).

Crystal, D. (1997). English as a global language. Cambridge: Cambridge University Press.

Greenbaum, S. (1996). Comparing English worldwide: The International Corpus of English. Oxford: Oxford University Press.

Hansen, K. (1997). British English and International English - two debatable terms. In E. Schneider (ed.), Englishes around the world, Vol. 1 (pp. 59-70). Amsterdam: John Benjamins.

Hundt, M.; Biewer, C. (2007). The dynamics of inner and outer circle varieties in the South Pacific and East Asia. In M. Hundt et al. (Eds), Corpus linguistics and the Web (pp. 49-70). Amsterdam, Rodopi.

Kachru, B. (1988). The sacred cows of English. English Today, 16, 3-8.

Leitner, G. (1992). English as a pluricentric language. In M. Clyne (Ed.), pp. 179-237.

Mauranen, A. (2006). English in the hands of non-natives - what's going on? Plenary address at ICAME Conference \#27 (Helsinki).

McArthur, T. (1997). The English languages. Cambridge: Cambridge University Press.

McArthur, T(2002). World English and world Englishes. Language Teaching, 34, 1-20.

McConnell, G. (2003). Towards a scientific geostratigraphy for English. In J. Maurais and M. Morris (Eds), Languages in a globalising world (pp. 298-312). Cambridge: Cambridge University Press.

McCrum, R. (2006). So, what's this Globish revolution? The Observer (December 3).

McLellan, G. (2007). Asian lingua franca English: On the way to becoming a koine? Presentation at IAWE Conference (Regensburg).

Modiano, M. (1998). The emergence of mid-Atlantic English in the European Union. In H. Lindquist et al., The major varieties of English (pp. 241-8). Vaxjö: Växjö University Press.

Newport, W. (1987). The coming of TEIL. English Today, 11, 9-11. 
Ogden, C. K. (1930). Basic English: A general introduction with rules and grammar. London: Paul Treber.

Pakir, A. (1997). Standards and codification for World Englishes. In L. Smith and M. Forman (Eds), World Englishes 2000. (pp. 169-181). Honolulu: University of Hawai'i Press.

Peters, P. (1998). In quest of International English. In A Renouf (Ed.), Explorations in corpus linguistics. (pp. 279-292). Amsterdam: Rodopi.

Peters, P. (2003). What is International English? In P. Peters (Ed.), From local to global English (pp. 33-39). Sydney: Dictionary Research Centre.

Peters, P. (2004). Cambridge guide to English usage. Cambridge: Cambridge University Press.

Peters, P. (2009a). The mandative subjunctive in spoken English. In P. Peters, P. Collins and A.

Smith, Comparative studies of Australian and New Zealand English (pp. 125-137).

Amsterdam: John Benjamins.

Peters, P. (2009, forthcoming). Standard British English. In A. Bergs and L. Brinton (Eds), Historical linguistics of English: An international handbook. Berlin, Mouton de Gruyter.

Quirk, R. (1981). International communication and the concept of Nuclear English. In L. Smith (Ed.), pp. 151-165.

Seidelhofer, B; Breitender, A; Pitzl, M.L. (2006). English as a lingua franca in Europe: Challenges for Linguistics. Australian Review of Applied Linguistics, 26, 3-14.

Sigley, R. (1999). Are we still under England's spell? Te Reo, 42, 319.

Smith, L. (Ed.) (1981). English for crosscultural communication: From practice to principle. London: Palgrave Macmillan.

Cite this article as: Peters, Pam. 2008. 'International English and its construction. Australian Review of Applied Linguistics special forum issue edited by Sharifian, Farzad; Clyne, Michael. 31 (3): pp. 35.1-35.10. DOI: 10.2104/aral0835. 